\title{
Analysis the Roots of Cultural Confidences From the Perspective of High and Low Context Cultures — A Case study of Burberry's Advertisement
}

\author{
Gao Yanmei ${ }^{1, \text { a }}$, Wang Yuan ${ }^{2, b^{*}}$ \\ ${ }^{l}$ School of Economics and Business Foreign Languages, Wuhan Technology and Business University, Wuhan, Hubei, \\ China \\ ${ }^{2}$ Department of Language and Literature, College of Technology, Hubei Engineering University, Xiaogan, Hubei, China \\ aginny1208@163.com \\ $b^{*}$ wyirene983@sina.com
}

\begin{abstract}
Burberry's New Year advertisement was introduced as a case in this article to illustrate the differences and conflicts between high context and low context cultures. The main differences between high and low context cultures lay in the following two aspects: the conveying of information and the interpersonal relationships. Whereas the three factors, religion, language and thinking mode and social history led to the root of such differences. On analyzing the roots of differences, it thus represents the characteristics of Chinese traditional cultures and manifest the roots of cultural confidences.

Keywords: High and low context cultures; roots of differences; cultural confidences; Burberry's advertisement

\section{从高低文化语境差异探讨中国文化自信的根源 - 一以巴宝莉广告为例}

\author{
高艳梅 ${ }^{1, a}$ 王媛 ${ }^{2, b *}$
}

${ }^{1}$ 武汉工商学院经济与商务外语学院, 武汉, 湖北, 中国

2 湖北工程技术学院新技术学院语言文学系, 孝感, 湖北, 中国

aginny1208@163.com

b*wirene983@sina.com

\section{摘要}

巴宝莉中国新年广告在中国市场受挫, 表明高低语境文化存在着差异和冲突。高低语境文化差异主要 体现在信息传播和人际关系两个方面，而差异的根源来自宗教因素、语言、思维方式因素和社会历史 因素三个方面。分析差异的根源正好反映了中国传统文化的特点, 从而进一步彰显了文化自信的根源。 关键词: 高、低语境文化; 差异根源; 文化自信; 巴宝莉广告

\section{1. 前言}

每一年的春节都是中华文化经久不息的情感盛宴, 是中华民族最具生机的文化节点和经济抓手。因此每一 年中国农历新年来临之际, 许多海外公司纷纷投放广告 以占领中国市场, 来自英国的高端奢侈品牌巴宝莉 (Burberry) 也不例外。“现代中国新年”, 这一广告的重 点是庆祝中国农历新年, 显示家庭成员团聚, 但它在中 国并没有被接受, 甚至连一些外国媒体也忍不住要批评。
许多中国人把它描述成一部鬼电影, 美国的 CNBC 用“恐 怖” 来形容这则广告。在大多数中国人看来, 这则广告 中模特儿的土灰色调和哀伤的表情与想要表达的合家 欢乐的气氛背道而驰。究其原因, 汉语文化是一种高语 境文化，而英语文化是一种低语境文化。

高低语境文化形成有着深刻的社会历史原因, 深受 语言观和思维方式以及宗教哲学的影响。深究差异的根 源, 发现中国传统文化有着天人合一, 螺旋式思维和集 体主义的特点, 这些特点无不彰显着中国文化的鬼米力和 自信。本文将从高低语境文化差异入手来分析中国的文 
化自信及其自信的根源。

\section{2. 高低语境文化和文化自信的定义}

高语境文化和低语境文化概念是由人类学家爱德 华・霍尔在他 1976 年出版的《超越文化》一书中首次 提出的。高语境文化是指主要通过使用语境要素 (例如 肢体语言、人的地位和声音语调) 来传播交际规则的文 化, 而不是直接、明确地表达观点。相反, 在低语境文 化中, 信息传递主要依赖于语言, 它是通过语言准确、 清晰地表述出来的 ${ }^{[1]}$ 。也就是说, 在言语交际过程中, 如果大部分信息都存在于物质语境中, 且话语意义的表 达高度依赖于语境, 这种文化就是一种高语境文化。反 之, 如果只有少量的信息包含在隐含的环境中, 大部分 的信息是通过言语表达的, 我们称之为低语境文化 ${ }^{[2]}$ 。 不难看出, 信息传播过程中对语境的依赖程度是区分和 判断一种文化属于高语境文化还是低语境文化的重要 指标。

霍尔和一些学者提出了一个从高语境到低语境的 民族文化区分图，其顺序如下：日本人、中国人、韩国 人、非洲裔美国人、美洲土著人、阿拉伯人、希腊人、 拉丁人、意大利人、英国人、法国人、美国人、斯堪的 纳维亚人和德国人 ${ }^{[3]}$ 。中国文化是一种高语境文化, 而 包括英国和美国在内的西方文化是一种低语境文化。

文化自信是一个民族、一个国家以及一个政党对自 身文化价值的充分肯定和积极践行, 是对自己文化生命 力的坚定信心。习近平主席多次强调中国有坚定的道路 自信、理论自信、制度自信, 其本质是建立在五千多年 文明传承基础上的文化自信。文化自信包涵三个方面: 中国传统文化, 革命文化和社会主义先进文化, 而中国 传统文化是文化自信的根源。

中国传统文化博大精深、源远流长; 兼容并蓄, 和 而不同。从儒家之礼, 到道家之道, 再形成佛教的宗教 伦理道德思想体系, 中国传统文化是反映中华文明演进 的民族特质和风貌的一种民族文化, 是世世代代的中华 民族在几千年的繁衍生活中继承和发展的起来的优良 传统文化。它主要体现在三个方面: 一是和合精神, 中 国传统文化注重和谐, 个人与他人, 个人与群体, 个人 与自然皆能和谐相处, 紧密联系, 形成一种家国文化。 二是兼容并蓄的魅力, 中国古代北方少数民族屡屡侵犯 中原并建立政权, 企图用少数民族文化消融华夏文化, 但最终都被华夏文化所同化。正是在一次次碰撞和消融 过程中, 中国传统文化包容性增强, 更加有活力。三是 民本思想, 中国传统文化究天人之际, 通治国安邦之策, 民本思想贯穿始终 ${ }^{[4]}$ 。

\section{3. 高低语境文化之间的差异}

人们通常根据语言群体、国籍或地区社区来定义 “高”和 “低” 的语境文化。在本文中, 笔者对 “高” 和 “低” 的语境文化进行了界定, 以中国为高语境文化
的代表而美国为低语境文化的代表。

一般来说, 高、低语境文化主要差异体现在信息传 播和人际关系两个方面。信息传播的差异主要表现为语 言和非语言差异; 人际关系的差异体现在集体主义和个 人主义之间的差异。

信息传递过程中，我们不仅使用语言文字，还使用 我们的行为或非言语交流。由于不同的国家具有不同的 沟通方式，所以高低语境文化之间的语言和非言语沟通 之间肯定存在差异。

\section{1. 语言和非语言的差异}

信息主要是通过显性语言传递的, 我们称它为言语 交际, 语言作为表达思想的一种手段, 是传递信息的主 要工具。非言语交际, 包括眼神交流、手势、面部表情、 沉默、身体接触、说话人之间的距离、时间概念等, 在 高语境文化中起着重要的作用。另一方面, 在低语境文 化中, 信息传递很少依赖非语言交际。比较高低语境文 化, 言语交际与非言语交际在信息传播方面存在以下差 异。

\section{1. 1. 沉默的差异}

在高低语境文化中, 对沉默的态度是不同的。前者 赞扬沉默, 后者在交流中避免沉默。在高语境文化中, 人们在交流中重视沉默, 在他们的观点中, 沉默和停顿 有很多意义。沉默既可以表达同意, 也可以保留自己的 观点 ${ }^{[5]}$ 。在中国传统文化中, 沉默被当作谦逊和美德, 从 “沉默是金” 可见一斑。然而, 在低语境文化中, 人 们主要用语言交流, 他们认为沉默是缺乏信心。如果谈 话之间出现沉默，沟通者就会感到尴尤。

\section{1.2. 时间的差异}

在高语境文化中, 人们有一个以过去时间为导向的 多维时间系统。在这个时间维度下，他们通常同时做几 件事, 因此重要的是过程, 而不是结果。而低语境文化 中的人采用面向未来的单一时间系统。他们把时间当作 一条直线, 有计划周密的时间表, 并严格按照时间表的 安排行事。时间处理在高语境文化中是非常灵活的, 但 在低语境文化中，人们遵循严格的时间线，更加注重办 事的效率和结果。

\subsection{3 空间和触觉的差异}

人们安排空间的方式反映了他们之间的距离, 以及 是否想要接触、互动。高语境文化中的人们共享相同的 空间, 可以彼此生活或工作, 他们很少表达自己的属地 感。由于缺乏这种感觉, 他们彼此会站得很近, 身体接 触会很多。在同性别中也会表达出特别亲密的关系。而 
在低语境文化中, 人们很看重个人的隐私, 有强烈的属 地感, 他们彼此站得很远, 会利用周围物体来增加和其 他人之间的距离, 并且倾向于分开和不接触。

高语境文化对非言语交际的重视程度较高，对言语 交际的重视程度较低, 信息主要通过隐含的交际语境来 传达。相反, 低语境文化更注重言语交际, 绝大多数的 信息都通过言语传递, 非言语很少起作用, 低语境文化 更倾向以一种直接和明确的方式传达信息。

\section{2. 集体主义和个人主义}

霍夫斯泰德的文化维度理论将集体主义和个人主 义的概念应用于高低语境的文化中 ${ }^{[6]}$ 。一般来说, 高语 境文化有点集体主义，低语境文化倾向于个人主义。从 信息传播角度来看, 高语境文化的人比低语境文化的人 站得更近, 这意味着他们更有可能发展彼此之间的密切 关系。

高语境文化传播者重视保持和谐与紧密的人际关 系。他们也关心别人的 “感情和面子”, 所以更喜欢一 种间接和含蓄的沟通方式, 试图避免争端和不愉快。另 一方面, 低语境文化的传播者更重视个人的诉求和平等 的沟通。沟通的方式是直接和明确的, 他们通常简单直 接地表达自己观点, 很少关心的别人的感受以及面子, 也很少注意观点的表达是否会伤害彼此之间的亲密关 系。

概括地说, 高语境文化是关系型的、集体主义的和 重交际的。他们高度重视人际关系, 群体成员是一个非 常紧密的社区 ${ }^{[7]}$ 。相反, 低语境文化不那么紧密, 个人 的信息传递有更少的设定线索。

\section{4. 高低语境差异彰显了文化自信}

文化语境的高低不是一蹴而就的, 其形成有着诸多 原因。本文将从宗教差异, 语言观与思维方式以及社会 发展史几个角度来探寻差异根源, 进而分析中国文化自 信的根源。

\section{1. 宗教差异}

宗教差异被认为是最重要的原因。在中国, 儒学、 道教和佛教对中国的高语境文化有着重要的影响。儒家 文化认为, 少言、葟言、慎言是值得赞扬的美德, “巧言 令色, 鲜矣仁”。《论语》中的许多警句清楚地传达了这 些思想，如 “君子欲衲于言，而敏于行”。道教文化的核 心是 “道” , 也是中国传统哲学的核心概念, “道” 是无 限的、永久的、恒定的, 与 “道” 相比, 所有可感知的 事物都是有限的、暂时的、偶然的和可变的, 精神的最 高境界是 “悟道”。老子认为 “知者不言, 言者不知”, 庄子认为 “得意忘言”, 文学追求的境界是 “意在言外” “言有尽而意无穷”。佛家文化也很早意识到语言的局 限性, 禅宗提倡采用坐禅冥想的方式进行超越语言的交
际。“不立文字，教外别传”，“言语道断，以心传心”; 会心处不假无二, 相应处无不在心。佛家讲究意会, 明 心见性, 大彻大悟, 这是 “悟” 的境界, 完全超越了语 言作用 ${ }^{[8]}$ 。唐宋时期, 儒、佛、道三种宗教思想成功合 融, 形成了中国传统哲学, 影响着中国文化追求的境界 是 “语言是有限的但意义是无限的”。

与东方佛教相比, 大多数西方国家信奉基督教, 基 督教主导着西方文化, 美国也不例外。基督教强调个人 主义, 如自由、平等和博爱。基督教徒相信, 上帝用他 神奇的话语创造了整个世界，并赋予人们生存的权利。 根据圣经所述, 语言和上帝共存, 上帝就是语言, 上帝 用语言创造了全世界。总之, 基督教强调语言的重要性。 人们在日常生活中自然地通过言语与上帝沟通。人的语 言是沟通最重要、最直接的工具, 因此会使用语言的人 类就被认为是万物之灵。

中国高语境文化的核心思想是天人合一，人的语言 是有限的, 自然的道法是无限的, 要把有限的语言融入 到无限的自然之 “道” 中。这种天人合一的哲学思想, 其 实质是推崇 “和”, 即人与自然和谐相处, 人与自然共存 共荣, 绿水青山就是金山银山, 倡导有节制地适度地开 发利用自然资源, 实行可持续发展。低语境文化认为

“人是万物之灵”，人与自然关系表现为征服和控制的 强烈欲望——战胜, 人定胜天, 这是一种天人二分的思 想。这种思想把人当作自然界的主人，不断地改造和征 服自然。人与自然的分裂带来的后果是过度发展, 破坏 生态平衡。因此很多西方学者在解决全球自然环境问题 时转向了中国传统哲学。这种天人合一的精神正是文化 自信的根源。

\section{2. 不同的语言观和思维方式}

汉语是一种以联想思维为特征的 “审美” 语言, 更 多地使用暗示、隐喻和意象, 尤其是中国诗歌是审美语 言的代表 ${ }^{[9]}$ 。此外, 汉语也是一个话题突出性结构语言, 强调意合。在汉语中, 词语和句子之间的逻辑联系是通 过语义的连贯来实现的, 而不是通过结构形式的连接来 实现的。在这种结构中, 话题和述题之间没有像英语一 样的严格的一致关系, 人们只需根据话题的需要来陈述 要表达的内容, 说话者的意愿决定了整个句子结尾的位 置, 因此语句的结构呈现出开放性的特点, 话题和述题 可以无限延伸 ${ }^{[10]}$ 。语言是思维的载体, 思维方式和语言 具有相关性。由于话题突出型语言结构是一种演绎语言, 与其相关的思维方式是螺旋式的。中国人表达自己的观 点时, 首先引用大量证据, 螺旋式、绕圈子般地逐步接 近论点, 最后在强大的论据支撑下千呼万唤始出来地表 明自己的观点。这种思维方式强调直觉顿悟和对事物的 整体思考, 以主体意向性为出发点。在这种思维模式影 响下, 认识和改造客观世界首先把个人放置到整个宇宙 中去感悟, 这是一种整体观思想 ${ }^{[11]}$ 。这种整体观的高语 境文化包容性更强, 能够包容一切文化, 因此对待其他 文化能够求同存异，接受有差异的文化，秉承和而不同 的观念, 珍视自身优秀文化的同时又尊重对方文化, 寻 
求不同文化的和谐相融 ${ }^{[12]}$ 。这是文化自信的根源。

相反, 英语是以因果关系为特征的 “理性” 和 “逻 辑” 的语言, 注重语言的建构和推理。更重要的是, 英 语是一种主语突出结构的语言, 这种结构中的主语和谓 语的关系由特定的形式规则即一致关系相约束, 这些规 则在表达观点必须被遵循, 否则就是错句。这些规则限 制了主语和谓语之间的联系, 而主语和谓语是句子的根 本骨干, 是句子的主要成分, 不可或缺, 因此假如要扩 展一个句子, 只能在这一封闭的结构内, 通过一些关联 词来扩展句子中某一部分。而正是由于这种严密的语言 结构, 其带来的思维方式也是线性的, 倾向于直接表达 观点。在语段的形成过程中, 说英语的人会在一开始就 一语中的, 随后层层推进, 用推理的手段摆出个人的论 据, 其间很少出现半点与论点无关的语言。这与汉语的 螺旋式思维风格迥异。

主语的紧密结构强调理性和逻辑的语言, 这种理性 和逻辑又造就了思维方式的推理性, 即找到 “是什么” 的根源, 也就是一元论思想。一元论思想认为文明只应 该有一种模式, 发展也只有一条道路, 而其他文明和道 路都是要同化、压制、甚至毁灭的异端邪说。这种非此 即彼、非黑即白的一元化思维模式使得人类文明冲突和 矛盾不断, 已经日益威胁到人类赖以生存的环境。而中 国传统文化具有极大的包容性，儒家强调 “和而不同”、

“和实生物”, “和” 强调的正是差异性和共存性, 这正 是中国文化自信的表现。

\section{3. 不同的社会史}

不同的社会史是造成高低文化语境的重要原因之 一。在中国历史上, 漫长的封建社会的礼教限制了人们 的语言和思想。大陆为主的地理环境带来了几千年的农 业文化, 稳定的农业生产使人们不必到处旅行, 长期处 于安定的、共同的社会环境中。同时, 对农业的重视, 使人们依靠自然, 尊重自然, 倡导 “天人合一”的思想。

由于人们世世代代生活在稳定的家庭和人口很少流动 的土地上，因此形成了同样的环境和集体主义思想。

同样的生活环境生成了同样的语境, 信息传递可以 依靠语境, 而无需直截了当。同时, 集体主义思想提倡 社会、国家, 家庭的利益重于个人利益, 在必要的时候 甚至应该牺牲小我来顾全国家、团体的利益。因此中国 人做事之前首先考虑其所作所为是否与集体利益相悖, 是否伤害到集体环境中的其他利益, 这也是说话依靠语 境传递信息的原因, 避免太直白伤害到共同环境中其他 人。在集体主义思想下, 中华民族的伟大复兴是全体中 国人的共同梦想。

然而, 美国只有几百年的历史, 是一个人口结构复 杂、流动性大的移民国家。工业革命和技术的发展使美 国人更加注重效率和个人利益, 因此美国文化是个人主 义的, 提倡个人斗争和平等。由于缺乏共同的生活环境, 美国人更倾向于采用直接、明确的交流方式。

正是因为个人主义, 美国人强调个人和权利自由, 崇尚竞争。他们相信每个人有自己独特的个性, 并且应
该充分认识和发展这种特性。个人主义思想倡导最大程 度地实现自我价值, 追求自由、平等, 为了实现这些权 利会积极主动竞争，而在竞争过程中，难免会为了个人 利益而忽视他人感受 ${ }^{[13]}$ 。美国人追求的美国梦是个人主 义至上的, 推崇个人自我价值的实现来促进社会的进步 和发展。而中国梦是把整个国家和民族的理想放置到唯 物史观中，实现的主体是全体人民，中华民族的伟大复 兴是靠全体人民实现的，而不是某一个特定的个体的力 量, 中国梦实现了, 每个人的梦也实现了。从这一层次 来看, 中国文化比较高级, 更加自信。

\section{5. 结语}

随着全球一体化的发展，国家、民族间的跨文化交 际活动越来越频繁, 英语作为一门国际交流工具, 是各 种跨文化交际包括商业活动中使用最频繁的语言。作为 一种低语境导向的语言, 在跨文化交际活动中要考虑高 语境文化的差异和交际特点，才能在交际中取得成功。 诸如宝巴莉公司的新年广告, 直接把低语境导向的西方 文化应用于高语境导向的中国文化, 忽视了高语境文化 中环境和氛围的作用, 犯错误在所难免。对比低语境西 方文化的天人二分、线性思维和个人主义特点, 正好彰 显了我国传统文化的天人合一、螺旋型思维和集体主义 特点, 这正是我们文化自信的根源。

\section{References}

[1] Hall, E.T. (1976) Beyond Culture. Doub., New York.

[2] Hall, E.T. (1993) Understanding Culture Difference Germans, French and Americans. Intercul. Press Inc., Yarmouth.

[3] Xu. L.S. (2004) Intercultural Communication. SFLEP, Shanghai.

[4] Guan, Y. (2017) Inheritance and development of Chinese traditional culture from the perspective of scientific development. J. Harbin Univ. Comm, 122: 125-126.

[5] Zhang, L.N. (2005) High-context and low-context culture communication. J. Huaihai Inst. Tech (Soc. Sci. Ed.), 9: $56-58$

[6] Elizabeth, W. (2006) Intercultural communication on web sites: a cross-cultural analysis of web sites from highcontext cultures and low-context cultures, [J]. CMC, 11: 274-299.

[7] Li, T. (2016) Comparative study on origin and communication differences of high-context and low-context cultures. J. Shenyang Univ. Tech. (Soc. Sci. Ed.), 9: 189-192.

[8] Wang, H.Z., Liu, Z.X. (2015) On high-context and lowcontext cultures in intercultural communication. J. Hubei 
Univ. Econ. (Hum. Soc. Sci.), 12: 110-111.

[9] Li, T. Communication strategies in the perspective of high-context and low-context cultures. J. Hainan Norm. Univ. (Soc. Sci. Ed.), 169:140-144.

[10] Zhao, J.J., Wang, Y.B. (2013) A contrastive study of syntactic structure in Chinese and English - "topiccomment" in Chinese and "subject-object" in English. J. Hubei Norm. Univ. (Phil. Soc. Sci.), 33: 60-62.

[11] Hu, H.M. (2013) To be text-oriented or not - a

contrastive study of the Sino- western ways of thinking. J. Shanxi Agric. Univ. (Soc. Sci. Ed.), 12: 569-570.

[12] Fang, Y. (2017) Philosophical thinking of cultural selfconfidence from the perspective of cultural differences between China and the west. J. Edu. Teach. Forum, 43: 8889.

[13] Ding, X.Y. (2010) Comparison of value between china and American in cross-cultural communication: discussion on collectivism and individualism. J. Tonghua Norm. Univ. 31: 76-78. 